\title{
Enhancing Population's Resistance to Toxic Exposures as an Auxilliary Tool of Decreasing Environmental and Occupational Health Risks (a Self-Overview)
}

\author{
Boris A. Katsnelson1, Larisa I. Privalova1, Vladimir B. Gurvich1, Sergey V. Kuzmin 1,2, \\ Ekaterina P. Kireyeva1, Ilzira A. Minigalieva', Marina P. Sutunkova1, \\ Nadezhda V. Loginova1, Olga L. Malykh², Sergey V. Yarushin'1, Julia I. Soloboyeva1, \\ Natalia I. Kochneva ${ }^{2}$ \\ ${ }^{1}$ Medical Research Center for Prophylaxis and Health Protection in Industrial Workers, Ekaterinburg, Russian \\ Federation \\ ${ }^{2}$ Sverdlovsk Regional Office of the Federal Service on Supervision in Sphere of Protection of the Consumers' \\ Rights and Well-Being of a Person (Rospotrebnadzor), Ekaterinburg, Russian Federation \\ Email: $\underline{\text { bkaznelson@ymrc.ru, bkaznelson@etel.ru, honored sci@yahoo.com }}$
}

Received 14 August 2014; revised 12 September 2014; accepted 5 October 2014

Copyright (C) 2014 by authors and Scientific Research Publishing Inc.

This work is licensed under the Creative Commons Attribution International License (CC BY). http://creativecommons.org/licenses/by/4.0/

(c) (i) Open Access

\begin{abstract}
Environment chemical pollution can be persistent, and even virtually irremovable. For some chemicals in the workplace environment reliably safe low exposure levels are technically unattainable or presumably nonexistent. As a supplement to decreasing harmful exposures to as low levels as possible, the "biological prophylaxis" aims at enhancing host's protective mechanisms. During over 30 years in animal experiments modeling isolated or combined chronic or subchronic exposures to silica, asbestos, monazite, lead, chromium, arsenic, manganese, nickel, vanadium, nanosilver, nanocopper, formaldehyde, phenol, naphthalene, benzo(a)pyrene we tested so-called "bioprophylatic complexes" (BPCs) comprising innocuous substances with theoretically expected beneficial influence on the toxicokinetics and/or toxicodynamics of those toxics. The BPCs proved protectively effective in animal experiments were then subjected to controlled field trials on restricted groups of volunteers. Once the effectiveness and safety of a BPC was established, it was recommended for practical use, first of all, in the most vulnerable population groups (children, pregnant women) and in the most harmful occupations. At each stage of this work the effectiveness of the bioprophylactic approach to chemical risks management was successfully demonstrated. The BPCs tested up to now proved capable of mitigating systemic toxicity, cytotoxicity, fibrogenicity, and mutagenicity of the above-listed chemicals.
\end{abstract}




\section{Keywords}

\section{Environmental Pollution, Health Risks, Bio-Protectors}

\section{Introduction}

Obtaining evidence of association between certain health impairments at the population or subpopulation level and exposure to specific harmful factors of the environment (or even an integrated estimate of its adversity) and using established exposure-response dependences for prognostic assessment of health risks are not the ultimate goal of environmental epidemiology; rather, they present a prerequisite to creating a system for managing these risks. A widely used term "interventional epidemiology" usually implies planning and implementing epidemiological study designed as to test a hypothesis about the association between exposure to harmful factors of the environment and certain health impairments at the population level by modifying exposure conditions. In such a study researchers intervene to change reality, and then observe what happens. Thus the intervention into exposure-response relationship is used as a research methodology rather than a goal in itself. We propose, on the contrary, to look for epidemiologic justification of an intervention as a preventive strategy.

Furthermore, we maintain that an intervention can be aimed not only at exposure sources and pathways but also at the receiving end of its impact—sensitive human beings. It is where what we define below as "biological prophylaxis" comes into the framework of the interventional epidemiology. One should take into consideration that the current status of the economy and technology too often (and not only in developing countries) does not allow to reduce numerous harmful environmental exposures down to reliably safe levels. It is especially difficult to achieve when health risks are due to persistent pollution of soils in industrialized areas, for instance, with toxic metals. Besides, some exposures are quite likely to be harmful at even very low levels (for instance, to metal and metal oxides nanoparticles) and for some harmful chemicals absolutely safe levels of exposure are deemed impossible (genotoxic carcinogens being the most important example). Therefore, medico-biological sciences, to which environmental epidemiology belongs (even if it is often practiced by biostatisticians without cooperation with medical doctors) cannot withdraw from the search for ways of increasing organism's resistance to harmful impacts.

We defined this approach to managing health risks as "biological prophylaxis" as it deals with the response and resistance of the organism to harmful environmental factors, i.e. with biological prerequisites to the development of an occupational or environmental disease rather than with harmful environmental factors proper. The ultimate goal of biological prophylaxis is to reduce the probability of developing a disease or preclinical condition caused by a certain harmful exposure or combined exposures. This goal, however, may be achieved by employing essentially different approaches. One of them, feasible only in industry, is to reduce the probability of employing individuals whose sensitivity to harmful factors associated with a particular job exceeds considerably the average level. Using genetic, physiological and biochemical methods for testing such sensitivity it can be possible to identify a subpopulation of employees with a reduced probability of suffering from the harmful effects of these factors. A good example is provided by long-term studies which allowed us to reveal a set of features characterizing individual predisposition to silicosis [1]-[5].

Another approach is based on the use of certain influences on an individual organism. They have to be reliably harmless on their own, but should enhance the resistance of the organism to a harmful environmental factor or factors. This individual-oriented approach may also involve complete exclusion or, at least, restriction of the household, food and other influences on the organism that (whether undoubtedly harmful per se or even safe outside the conditions of an accompanying harmful exposure) may increase the sensitivity of the organism to this exposure. Thus one may distinguish between active and passive individual biological prophylaxis, but this paper deals only with the former.

We investigated this particular field for a few decades, first of all, in animal experiments modeling chronic or subchronic exposures to silica [3] [6], asbestos [7], monazite [8], lead [9] [10], fluoride [11], chromium, arsenic, manganese, nickel, vanadium [12], nanosilver [13], nanocopper [14], formaldehyde [15], phenol, naphthalene, benzo(a)pyrene, different combinations of these toxics [9] [10] [12].

The bioprotectors tested included sodium glutamate, phytogenic adaptogens, for example, from the Araliacae 
family, individual vitamins, multivitamin and multimineral preparations, pectin enterosorbents, certain aminoacids (glutamate, glycine, methionine, acetyl cysteine), calcium supplements, biotic doses of trace elements (copper, iodine, iron, selenium), fish oil preparations rich in $\omega$-3 PUFA, iodine and hydrogen sulfide baths, pulsed electromagnetic fields, and also various combinations of these agents and factors. Some of them have been tested, upon careful experimental checking, in controlled field trials on humans in a real context—examples will be provided in this paper below.

The sum of these studies has provided a certain system of theoretical principles, allowing us to carry on an even more focused search for new ways of enhancing the effectiveness of biological prophylaxis. In what follows we will try to summarize these principles, illustrating them by a few examples.

\section{Theoretical Premises of Active Biological Prophylaxis and Examples of Experimental Studies}

A flow chart (Figure 1) presents schematically the main blocks of the systemic approach to the search for bioprotectors. Generally, it is based on the use of:

1) Means and interventions aimed primarily at increasing the effectiveness of natural mechanisms of detoxication and/or elimination of toxics and their metabolites, and thus, at reducing the retention of a harmful substance in the organism and especially in target organs ("toxicokinetic bioprophylaxis").

2) Means and interventions aimed at enhancing the functional reserves at all levels of the organism affected by toxic substance; at increasing the effectiveness of repair and compensatory processes; and at using physiological and toxicological antagonisms ("toxicodynamic bioprophylaxis").

A typical example of toxicokinetic bioprotectors is presented by enterosorbents (in particular, beetroot and apple pectin preparations, which have been extensively tested in our studies), preventing both primary absorption of toxic metals in the intestines (where they get not only through the mouth but also as a result of elimination, via the pharynx, of low-soluble particles initially deposited in the respiratory tract) and re-absorption of metals in the same intestines where they are excreted to by the liver. Pectins are included in all BPCs successfully tested so far in our experiments with toxic metals listed in the Introduction.

For organic toxics, however, the most important toxicokinetics mechanisms of defense depend on metabolic

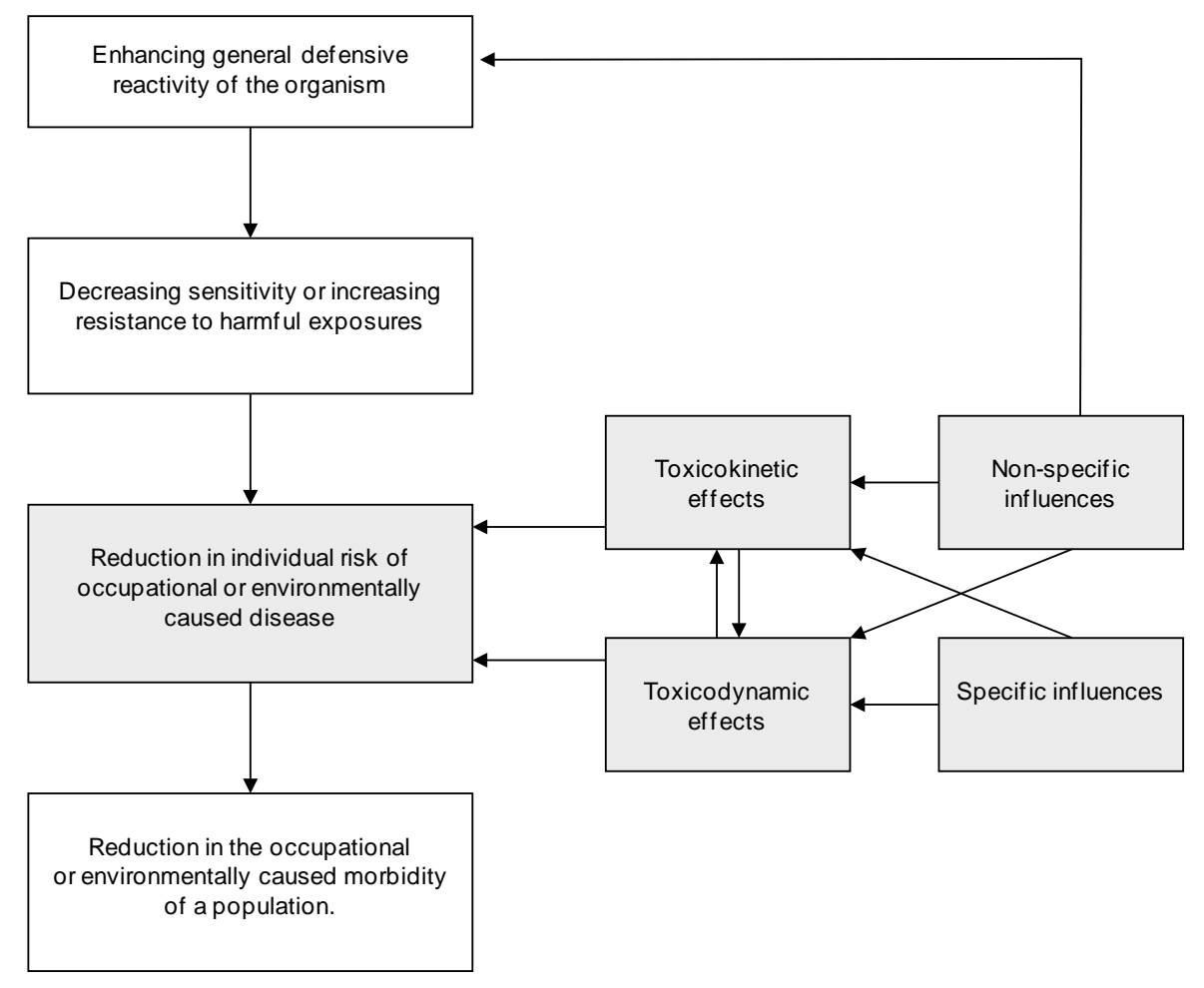

Figure 1. Schematic presentation of the active biological prophylaxis. 
biotransformation resulting either in oxidation products (up to $\mathrm{CO}_{2}$ and $\mathrm{H}_{2} \mathrm{O}$ ) or in soluble conjugates capable to be excreted with urine and bile. For organic chemicals having no reactive nucleophilic groups (e.g. for PAHs) the necessary prerequisite of conjugation is again the oxidative phase of biotransformation. That is why in our experiments we obtained beneficial toxicokinetics effect of oral administration of the reduced glutathione precursors (glutamate, glycine and methionine, the latter acting through transformation into cysteine ${ }^{1}$ ) not only against formaldehyde but against naphthalene as well.

Typical toxicodynamic bioprotectors are not only the same glutamate and some other amino acids, but also Saparalum (a preparation of Aralia mandshurica), vitamins, and also essential elements which act as antagonists of toxic metals (e.g. calcium, iodine, copper, iron, and, possibly, zinc —as antagonists of lead; selenium, calcium, copper-as antagonists of silver).

However, these two aspects of active biological prophylaxis (toxicokinetic and toxicodynamic ones) are almost inextricably interrelated and interdependent, as it is shown by the same diagram. Indeed, reducing retention of a harmful substance in the organism and especially in target organs inhibits the development of a pathological process (in other words, a toxicokinetic bioprotector produces a beneficial toxicodynamic effect). On the other hand, primary enhancement of resistance to the damaging action of this substance on the cells and organs which control the processes of its elimination or detoxication (pulmonary macrophages, liver, kidneys) maintains the effectiveness of these processes and, thus, reduces the retention of the toxicant in the organism (so we see a beneficial toxicokinetic effect of a toxicodynamic bioprotector). As can be seen from the results of one of our experiments (Table 1), nearly the same reduction in the concentration of lead in the blood $(\mathrm{PbB})$ as ensured by beetroot pectin was provided by such primarily toxicodynamic protectors as glutamate and calcium [16].

This is only one of the examples of the interrelation under consideration, which we observed often with regard to the attenuation of chronic intoxications due to not only lead but also arsenic, chromium or fluoride. Glutamate has also been repeatedly shown as the most effective agent for reducing the retention of silica particles in the pulmonary tissue and extrapulmonary lymph nodes [3] [6], although it does not stimulate particle elimination mechanisms, rather protecting one of these mechanisms (pulmonary phagocytosis) from damage, i.e. basically it operates as a toxicodynamic bioprotector. A similar effect has been shown also in experiments in which the efficacy of a complex including glutamate and a number of other toxicodynamic bioprotectors was tested under exposure of rats to chrysotile asbestos [7] or to monazite [8]. The enhancement of formaldehyde biotransformation into formic acid demonstrated by us was beneficial not only because it decreased the inner dose of the former (being the first step to its complete oxidative detoxication) i.e. acted as a toxicokinetics-oriented bioprotector, but also because such transformation is an alternative to the participation of formaldehyde in reactions with bio-macromolecules, which is the toxicodynamic basis of its toxicity and carcinogenicity [17].

Such bilateral interdependence of toxicokinetic and toxicodynamic effects demonstrated for the bioprotectors

Table 1. Comparison of certain effects of biological protectors against experimental lead intoxication $\left(X \pm S_{\mathrm{x}}\right)$.

\begin{tabular}{|c|c|c|c|c|c|}
\hline \multirow[b]{2}{*}{ Index } & \multicolumn{5}{|c|}{ Groups of rats administered lead and: } \\
\hline & Nothing & Pectin & $\begin{array}{l}\text { Sodium glutamate } \\
\text { (SG) }\end{array}$ & $\begin{array}{l}\text { Calcium gluconate } \\
\text { (Ca) }\end{array}$ & Pectin + SG + Ca \\
\hline $\mathrm{Pb}$ in blood, $\mu \mathrm{g} / \mathrm{ml}$ & $5.02 \pm 0.72$ & $1.94 \pm 0.21^{*}$ & $2.20 \pm 0.38^{*}$ & $3.17 \pm 0.68^{*}$ & $2.09 \pm 0.27^{*}$ \\
\hline $\begin{array}{l}\text { Reticulocytes per } 1000 \\
\text { erythrocytes }\end{array}$ & $178.8 \pm 13.5$ & $190.5 \pm 19.3$ & $125.5 \pm 7.5^{*}$ & $147.5 \pm 8.9$ & $154.9 \pm 24.3$ \\
\hline $\begin{array}{l}\text { Reduction in hemoglobin content } \\
\text { compared with baseline level, g/L }\end{array}$ & $55.0 \pm 3.6$ & $53.0 \pm 7.5$ & $47.2 \pm 4.6$ & $51.1 \pm 5.7$ & $35.6 \pm 4.6^{*}$ \\
\hline MDA in blood serum, $\mu \mathrm{mol} / \mathrm{L}$ & $0.28 \pm 0.01$ & $0.23 \pm 0.01^{*}$ & $0.26 \pm 0.01$ & $0.23 \pm 0.01^{*}$ & $0.24 \pm 0.01^{*}$ \\
\hline$\delta$-ALA in urine, $\mu \mathrm{mol} / \mathrm{L}$ & $357.0 \pm 37.1$ & $350.2 \pm 44.2$ & $278.9 \pm 25.4$ & $271.6 \pm 25.3$ & $278.9 \pm 32.8$ \\
\hline Coproporphyrin in urine, $\mathrm{nmol} / \mathrm{L}$ & $1522.3 \pm 242.6$ & $1266.9 \pm 161.2$ & $680.5 \pm 73.2^{*}$ & $935.5 \pm 146.9^{*}$ & $887.6 \pm 121.9^{*}$ \\
\hline $\begin{array}{c}\text { Activity of succinate dehydrogenase } \\
\text { (number of formazane granules per } 50 \\
\text { lymphocytes) }\end{array}$ & $414.0 \pm 7.0$ & $437.0 \pm 16.1$ & $504.2 \pm 1.2^{*}$ & $449.9 \pm 17.9$ & $515.6 \pm 14.1^{*}$ \\
\hline Calcium in blood serum, $\mathrm{mmol} / \mathrm{L}$ & $1.71 \pm 0.04$ & $1.86 \pm 0.10$ & $1.81 \pm 0.06$ & $1.79 \pm 0.08$ & $2.18 \pm 0.10^{*}$ \\
\hline
\end{tabular}

Note: “”, marks the indices for which the difference from the group that received lead only is statistically significant for $\mathrm{P}<0.05$ (Student's t-test).

${ }^{1}$ Later on we began to use not methionine but acetyl cisteine (e.g. [13]). 
under consideration was pronounced to a varying degree in response to the action of different harmful substances but, on the whole, can be considered as a consistent pattern.

According to another pattern that we have established, glutamate as an agent enhancing nonspecific resistance of the organism and, at the same time, improving the stabilization of cellular membranes through the activation of the bio-energy process which is essential to the cell, enhances to some extent (not only in vitro but also in vivo, when administered orally) the resistance of the macrophage to cytotoxic damage by different phagocytized particles of different chemical nature [18] in spite of the fact that the mechanisms underlying the cytotoxicity of silica and of low-soluble compounds of lead, fluorine, chromium or arsenic are not same. Given the fact that these chemical elements pollute the air mainly in the form of low-soluble particles and that the viable pulmonary (alveolar) macrophage is the main effector of pulmonary self-clearance from such particles, it becomes clear that this pattern has important practical implications.

Both toxicokinetic and toxicodynamic agents of active bioprophylaxis can be:

- more or less specific with regard to a particular toxicant if they interfere with the mechanisms of toxicokinetics and toxicodynamics pertaining exclusively to it (or at least with ones that play a key role just for this intoxication) - e.g. thiamine and methionine for arsenic intoxication, and calcium, iron, iodine and copper for lead intoxication;

- directed at mechanisms which are essential in the toxicokinetics and/or in toxicodynamics of a range of toxicants (an example is the protection of the macrophage by glutamate against the action of low soluble cytotoxic particles of different chemical composition);

- predominantly non-specific, if their effect is realized through such reactions at the organism level as the general adaptation syndrome (or the related concept of "non-specifically enhanced resistance" developed by the school of Nikolay Lazarev, an outstanding Russian toxicologist and pharmacologist), i.e. reactions increasing the effectiveness of various general protective mechanisms (the examples are glutamate and Saparalum).

One and the same bioprotector may in different cases either render a largely specific effect, acting on the key links of the toxicodynamics and/or a toxicokinetics (e.g. glutamate and also iodine baths and pulsed electromagnetic fields at exposure to silica, or the same glutamate as one of the GSH precursors at exposure to formaldehyde, or all the three GSH precursors and other antioxidant and free radicals scavengers as protectors against cytotoxicity and genotoxicity of nanometals) or help the organism mainly as an agent enhancing its nonspecific resistance (e.g. glutamate again for various chronic intoxications), but these types of protection are most likely to combine in any event.

The data presented in Table 1 also exemplify advantages of using several biopreventive agents in combination over their separate administration. In a subchronic experiment on rats exposed to lead acetate, it has been shown that the administration of a biopreventive complex (BPC) consisting of glutamate, pectin enterosorbent and calcium gluconate ensures a marked preventive effect [19]. Particularly noteworthy is the statistically significant reduction in the concentration of lead in the blood, approximately 2.4 times. At the same time, whereas the BPC did not demonstrate any particular advantages in terms of toxicokinetic effectiveness in comparison with glutamate alone or pectin alone, both of them, when administered separately, demonstrated a lower toxicodynamic protecting effectiveness judging by the set of different indices for organism's status in the groups which received either of them as compared with that given the complete BPC. Out of the 25 toxicodynamic parameters recorded in this study, a positive effect was observed only for 5 parameters in the group receiving pectin, for 7 in the group receiving calcium, for 8 in the group receiving glutamate, and for 12 in the group receiving the BPC. Additional evidence of higher efficacy of bioprotectors administered in a complex was provided by mathematical analysis of the data of this experiment using pattern recognition mathematics [19].

Using arsenic intoxication as another example, we have established that a BPC comprisng glutamate, pectin and vitamin $\mathrm{B}_{1}$, has a considerable advantage over the administration of these substances separately, in terms of both toxicodynamic parameters and accumulation of arsenic in the organism. Thus, the higher efficacy of complex bioprophylaxis in comparison with the effect of individual bioprotectors can also be regarded as a practically important consistent pattern. However, analysis of our findings indicates that, when searching for increased effectiveness of complex biological prophylaxis, it is advisable to test, first of all, combinations of agents for which the primary targets of the protective action and/or the basic mechanisms of such action are not fully the same.

By reducing the toxicity of a substance and its accumulation in target organs and cells by means of bioprotective agents, it proved possible to lower thereby the mutagenic (genotoxic) action as well if it is inherent in this 
substance. We showed it first for the action of arsenic and its combination with chromium, cadmium and lead [20] [21] and then for the action of formaldehyde [15], benzo(a)pyrene and multicomponent combinations including this PAH and mutagenic metals [21]. Such effect suggests reduced carcinogenicity which is associated for at least some metals which are carcinogenesis initiators (for example, for arsenic and chromium) with their genotoxiicity. This is a pressing problem for many industrial regions because metals polluting the environment in various combinations contain notorious carcinogens such as chromium, arsenic, nickel and cadmium. Examples of the antimutagenic activity of one of the biopreventive complexes tested by us are presented in Table 2. Note that in this micronuclear assay it was just the complete biopreventive complex, rather than its individual ingredients, that proved to be effective in inhibiting the action of arsenic. As was mentioned above, the higher protective efficacy of the same BPC in comparison with isolated bioprotectors at exposure to arsenic was also observed for toxicodynamic and toxicokinetic parameters.

Later on we demonstrated the antigenotoxic efficacy of a typical BPC in case of intoxication with a combination of benso(a)pyrene, arsenic, chromium, nickel, cadmium and fluoride, using quantitative tests for DNA fragmentation (the Comet assay and the RAPD test). It was found also that the inclusion into such BPC of a fish oil preparation rich in omega-3 polyunsaturated fatty acids (PUFA), presumably serving as precursors of eicosanoids known to enhance the DNA repair, additionally increased the anti-genotoxic action of a combination of ecotoxicants [21] as well as that of monazite particles containing thorium and uranium [8]. Therefore now we include such preparations in every BPC tested against chemicals with suspected genotoxicity—such as nano silver [13], nano copper oxide [14] and got so far positive results manifested by decrease in DNA fragmentation. A typical example is given by Table 3 .

A special theoretically challenging and practically important problem is the relationship between technogenic environmental pollution with some elements which in small doses are biologically essential and natural deficiencies of these elements. For example, the signs of copper deficiency in children residing in the Middle Urals townships (even against the background of undoubted pollution of the environment by the copper smelters emissions) are particularly adverse considering the contamination of this area with lead, which is a toxicological antagonist of copper. In an animal experiment we have shown that copper, even in low (biotic) doses, reduces

Table 2. The effect of experimental bioprophylaxis on the frequencey of mucronuclei $(\mathrm{MN})$ in polychromatophil erythrocytes (PChE) of rat bone marrow at subchronic intraperitoneal administration of: (a) arsenic oxide; (b) combinations of metals (arsenic-lead-chromium-cadmium).

(a)

\begin{tabular}{cc}
\hline Group & Number of MN per 1000 PChE \\
\hline Intact controls & $5.80 \pm 0.78$ \\
Pectin controls & $5.90 \pm 1.38$ \\
Arsenic & $\mathbf{7 . 5 0} \pm \mathbf{0 . 9 5}$ \\
Arsenic + vitamin $\mathrm{B}_{1}$ & $6.00 \pm 1.18$ \\
Arsenic + pectin & $6.25 \pm 0.86$ \\
Arsenic + glutamate & $5.40 \pm 1.03$ \\
Arsenic + the complex of all 3 protectors & $4.44 \pm 0.81^{*}$ \\
\hline
\end{tabular}

Note: *The difference from the "Arsenic" group is statistically significant for $\mathrm{P}<0.05$ (Student's t-test).

(b)

\begin{tabular}{cc}
\hline Group & Number of MN per 1000 PChE \\
\hline Intact controls & $3.75 \pm 0.83^{* *}$ \\
BPC controls (“Picovit”, Saparalum, pectin) & $4.86 \pm 0.81$ \\
Combination of metals & $\mathbf{6 . 5 5} \pm \mathbf{0 . 7 2}$ \\
Combination of metals + BPC & $4.71 \pm 0.69^{*}$ \\
\hline
\end{tabular}

Note: *The difference from the "Combination of Metals" group is statistically significant for $\mathrm{P}<0.1$ $(\mathrm{t}=1.9) ;{ }^{* *}$ Same for $\mathrm{P}<0.05$ (Student's t-test). 
Table 3. Coefficients of the genomic DNA fragmentation based on the results of RAPD-test in rats exposed to subchronic repeated intraperitoneal administration of silver nanoparticles with and without a bioprotective complex (BPC) $)^{2}, X \pm$ s.e.

\begin{tabular}{cccccc}
\hline \multirow{2}{*}{$\begin{array}{c}\text { Group of rats } \\
\text { exposed to }\end{array}$} & Liver & Bone marrow & Spleen & Kidney & $\begin{array}{c}\text { Nucleated cells of } \\
\text { peripheral blood }\end{array}$ \\
\cline { 2 - 6 } & $0.399 \pm 0.001$ & $0.385 \pm 0.003$ & $0.379 \pm 0.002$ & $0.385 \pm 0.003$ & $0.383 \pm 0.001$ \\
Water (controls) & $0.461 \pm 0.002^{*}$ & $0.455 \pm 0.032^{*}$ & $0.462 \pm 0.001^{*}$ & $0.423 \pm 0.008^{*}$ & $0.413 \pm 0.012^{*}$ \\
Nano-silver (NS) & 0.461 N $^{*}$ & $0.473 \pm 0.003^{*+}$ & $0.419 \pm 0.003^{*+}$ & $0.407 \pm 0.006^{*+}$ & $0.390 \pm 0.007$ \\
\hline NS + BPC & $0.408 \pm 0.011^{+}$ & 0.373 &
\end{tabular}

Note: Statistically significant difference ${ }^{*}$ from the control group; ${ }^{+}$between the group given NS together with BPC and the group given NS only (P < 0.05 by Student's $t$-test).

the harmful action of toxic doses of lead [22]. This suggests that it is advisable to include multimineral preparations containing copper into the BPC even for such environments.

Another example of widespread elemental deficiency, also especially unfavorable in combination with the environmental pollution with lead, is that of iron. Lead is known to inhibit the synthesis of hem thus impeding the utilization of iron. We have shown in two experiments with various toxic combinations comprising lead that the addition of an iron preparation to the BPC enhances its protective effect [17].

Another typical example of a relationship between intoxication-induced trace element disbalance and exogenous trace element deficiency pertains to the problem of iodine. The possibility of harmful action of toxic metals on the thyroid gland presents a special research interest for regions where multicomponent environmental pollution with such metals is combined with iodine deficiency and endemic goiter. It has been found in an experiment [20] that subchronic exposure of rats to a combination of lead, chromium, arsenic and cadmium (modeling the real pollution of the environment in one of such industrial towns with emissions from a copper smelter and chromium salt factory) caused the disturbance of the microscopic morphostructure of the thyroid gland and reduced the concentrations of the thyreotropic hormone and also of triiodothyronine and thyroxine in the blood. A BPC consisting of Saparalum, pectin enterosorbents, a multivitamin-multimineral preparation, a calcium supplement and an iodine preparation administered to rats orally throughout the period of exposure to the same combination of toxic metals slowed down the development of intoxication and produced a normalizing effect on the thyroid gland and thyreohormonal spectrum. The same BPC without an iodine additive was also found to be effective; however its beneficial effect both on the function of the thyroid gland and the hormone spectrum and on the systemic toxicity of the combination of metals was less marked.

The purpose of our experiments is to test BPC compositions that would be not only efficacious and safe but also convenient for subsequent practical use. We, therefore, prefer to include preventive doses of vitamins and trace elements in readymade balanced complexes in the form of commercial multivitamin-multimineral preparations rather than providing them separately. (With an eye to using the BPC tested for protecting not only adults but also children, we often chose for our experiments the preparations adapted for 4 - 7-year-olds, such as "Picovit" or "VITRUM Kids"). However, sometimes we correct these complexes with this or that supplement (e.g. with additional doses of ascorbic acid, calcium, iron, selenium or iodine) when there are grounds to suppose that some essential elements or vitamins are antagonists of a toxic the organism is exposed to, or that their requirement is increased under a particular stress.

\section{From Toxicological Experiments to Trials on Humans ${ }^{3}$}

When selecting a BPC composition for experimental testing based on the above theoretical considerations and earlier obtained experimental results, we deliberately forbear from testing any agents that have not yet been introduced into broad prevention practice. It should be emphasized that we do not consider it sufficient for a substance to have an official permit as a means of therapeutic treatment because requirements as to the safety of biological prophylaxis agents and pathogenetic therapy medications are basically not the same. Indeed, a possibility of side-effects does not preclude the clinical use of certain medications. In making a decision in each case, the physician has to compare the severity and probability of such side-effects with the severity and probability of

\footnotetext{
${ }^{2}$ Exposure parameters and composition of the BPC see [17].

${ }^{3}$ Both animal experiments and trials on humans were approved by the Commission on Ethics of our Research Center. Besides, we always received written consent from adult volunteers or children's parents to participate in such trials.
} 
an adverse course and outcome of a disease if a medication were not prescribed. Besides, the risk of a side-effect is reduced by ongoing or periodic medical supervision allowing treatment of a patient to be modified as required.

With regard to the use of a prophylactic agent, the situation is essentially different. First of all, it is offered to practically healthy people who are only likely to fall ill if they are not given this agent and, consequently, the possibility of harm from a presumably protective agent itself is inadmissible in principle. Secondly, broad translation into practice, i.e. exposure of large groups of people to this agent creates conditions for the realization of even those side-effects which have a very low probability of occurring at an individual level, whereas even single instances of explicit harm caused by a presumably beneficial agent may undermine trust towards the very idea of biological prophylaxis. Thirdly, medical supervision is practically feasible only at the stage of field trials of a preventive agent conducted on a limited group of people but not at subsequent broad use of it.

For these reasons, means and agents of biological prophylaxis, taken in recommended doses, should be as free from any harmful effect on the organism as can be reasonably established. Such relative guarantee is provided not only by the fact that people already use broadly, although for other purposes, practically all agents that we test as antitoxic bioprotectors or their analogues but also by the fact that in our animal experiments all BPCs are tested in parallel for any harmful side-effects on a group of laboratory animals not exposed to toxic substances.

As for controlled courses of bioprophylaxis on humans using BPCs (which may be regarded as field trials), not only are they possible, provided the above safety requirements are met, but also essential for confirming the positive effect obtained in animal experiments before recommending this or that method of bioprophylaxis for wide use. It should be noted, however, that before carrying out a course of bioprophylaxis it is compulsory to obtain informed written consent from adult volunteers and from children's parents.

Let us provide some examples illustrating the sequence of tasks whereby the search for, experimental and field testing, and then wide use of bioprotectors were preceded by epidemiological identification of specific risks for the health of a population with subsequent epidemiological assessment of the effect. Where in the following illustrations we give data "before" and "after" the course, "before" always means 1 - 2 days before starting administration of bioprotectors (or a placebo) while "after" -1 - 2 days after the end of the administration course which usually lasted one month. Treated and control groups were observed in parallel. Indices of interest depended on the particular study but comprised, as a rule, both toxicokinetic features (e.g. toxic metal's blood or urine concentration) and those characterizing the organism's status either integrally or, when possible, more or less specifically for the environmental or occupational toxic exposure under consideration.

Example 1.

The multi-sided health and development risks associated with exposure of young children and, moreover, of fetuses (through the cord blood) to lead constitute, virtually worldwide, one of the environmental medicine problems of the highest priority. Beginning from 1996, we have been and are still developing an on-going research and practical program aimed at assessing lead-induced risks for children (including prenatal impacts) in several most industrialized towns of the Sverdlovsk Region (Middle Urals, Russia), and then at abating these risks [23]. As we have found, there existed in the towns under study a considerable body-burden of lead in both preschool children and pregnant women (as estimated by their blood lead levels- $\mathrm{PbB}$ ), and in the foetuses of the latter (judging from lead levels in cord blood), this body-burden depending on the size and the proximity of copper smelters. Although these levels are, on average, similar to those reported from the USA and some European countries and are even lower as compared with some others, it has been demonstrated that (a) the prevalence of children's mental retardation in different towns correlated with PbB levels typical of them, and (b) the higher the $\mathrm{PbB}$ in cord blood, the higher the probability of some abnormal conditions in babies during the $1^{\text {st }}$ year of life and even later.

The US EPA “Uptake/Biokinetic Model for Lead” fed with available quantitative data on lead in different environmental compartments provided satisfactory predictions of both the average value and the dispersion of blood lead levels in children dwelling in different towns and, for one of them, in different periods. The model estimates of the contribution made by those compartments to the lead body burden were used for developing an adequate risk management strategy. The effectiveness of experimentally tested anti-lead BPCs (see above) was confirmed by field trials, and then administering these BPCs was included into the said scenarios which, when implemented even partly, has given considerable prophylactic effects manifested by both decreasing PbB levels and improving psychological status of children [23].

Good effect was obtained also in pregnant women as can be seen from data given in Table 4 based on the 
Table 4. Influence of bioprophylactic courses on the blood lead level in pregnant women.

\begin{tabular}{|c|c|c|c|}
\hline \multirow{2}{*}{ Year } & \multirow{2}{*}{ Number of pregnant women } & \multicolumn{2}{|c|}{ Blood lead level, $\mu \mathrm{g} / \mathrm{dL}(X \pm$ s.e. $)$} \\
\hline & & Before the bioprophylactic course & After the bioprophylactic course \\
\hline 2008 & 1119 & $3.09 \pm 0.19$ & $2.16 \pm 0.15$ \\
\hline 2009 & 81 & $2.83 \pm 0.33$ & $1.32 \pm 0.63$ \\
\hline 2010 & 461 & $3.44 \pm 0.25$ & $2.06 \pm 0.18$ \\
\hline 2011 & 558 & $3.76 \pm 0.33$ & $1.91 \pm 0.23$ \\
\hline 2012 & 593 & $2.74 \pm 0.15$ & $1.53 \pm 0.11$ \\
\hline 2013 & 515 & $3.25 \pm 0.31$ & $1.74 \pm 0.19$ \\
\hline Total & 3327 & $3.20 \pm 0.11$ & $1.90 \pm 0.08^{*}$ \\
\hline
\end{tabular}

Note: *The observed decrease in the mean PbB level on the merged dataset is staisrically significant at $\mathrm{P}<0.001$ (by the paired $t$-test).

merged yearly datasets for up to 13 townships and for the period 2008-2013, and in Figure 2 illustrating as an example results obtained on 9 different town cohorts under observation in $2007^{4}$. On the merged dataset for all towns and all years the decrease in the mean $\mathrm{PbB}$ was equal to $40.6 \%(\mathrm{P}<0.001)$.

Ettinger [24] noted a considerably lower reduction in $\mathrm{PbB}$ (on average, by $11 \%$ compared with those who received placebo) in 334 women as a result of administering only a calcium supplement from the 1st trimester to the end of pregnancy at a dose of $1.2 \mathrm{~g}$ /day. The initial mean PbB level was close to that in our cohorts. We believe that a higher efficacy of our intervention is due to the combined action of all BPC components including: pectin enterosorbent, glutamate, the multivitamin multimineral preparation "Vitrum Prenatal Forte" (Unifarm, Inc., USA), additional sources of calcium ("Calcium D3-Nycomed” by Nycomed Pharma, Norway), and iodine ("Iodomarin” by Berlin-Chemie and Menarini, Italy), and, besides, an iron additive ("Sorbifer Durules” by Egis, Hungary) for women with anaemia. Meantime, the total dose of calcium amounted to $1.05 \mathrm{~g}$ a day, i.e. was even lower than that used by Ettinger [24] and the duration of the BPC administration was shorter: only 30 days.

On a subcohort for which we got paired data on $\mathrm{PbB}$ in both mother's blood during the 32 - 34 weeks of pregnancy (that is just after the bio-prophylactic course) and in the cord blood we found a statistically significant positive correlation between the two values characterized by the Pearson's coefficient of $0.357(\mathrm{P}<0.05)$ and Spearman's coefficient of $0.406(\mathrm{P}<0.02)$. Thus lowering the maternal PbB with our intervention leads to decreasing foetus exposure to lead through the placenta and cord blood. Besides, it stands to reason that the intra uteri development of the baby to be born benefits also from attenuating subclinical lead intoxication of the pregnant mother-first of all, from hindering mechanisms of the lead anemia associated with impact on porphyrin metabolism. Indeed, it is a well established fact that anemia (iron deficiency anemia included) during pregnancy has significant adverse affect on the fetal outcome [25]. Therefore it has to be stressed that we observed a considerable reduction in the concentration of delta-aminolevulinic acid in the urine of the pregnant women given the BPC (across the merged dataset, from $40.36 \pm 2.50$ to $30.62 \pm 2.54 \mu \mathrm{mol} / \mathrm{L}, \mathrm{P}<0.05$ ) while the haemoglobin content of the blood, on the contrary, increased (from $115.5 \pm 1.17$ to $122.7 \pm 0.66 \mathrm{~g} / \mathrm{L}, \mathrm{P}<0.05$ ).

Example 2.

Another concern with regard to children's health in our region and, in particular, in the cities and towns located near the copper smelters is a considerably higher prevalence of kidney diseases as compared with the rest of Russia. Assuming that this situation may be connected with increased environmental exposure of children not only to lead but also to cadmium, we carried out two epidemiological studies, the methods and findings of which were described in detail by us earlier [26]. The results obtained in these two independent studies on children dwelling in 4 towns suggested that the combined cadmium and lead exposures that result in relatively low body burdens of these metals in children could cause a pre-clinical renal damage manifesting itself by an increase in beta 2-microglobulin urine concentrations (B2u) even though these were not above the widely recognized diagnostic level of $300 \mu \mathrm{g} / \mathrm{L}$.

Then in experiments on rats it was shown that: a) Both cadmium and lead, when administered repeatedly in low doses as single toxicants or in a dual combination, cause renal damage manifesting itself in a lot of functional, biochemical and morphometrical indices; b) In doses equivalent to fractions of respective acute $\mathrm{LD}_{50}$,

\footnotetext{
$\overline{{ }^{4} \text { Bioprophylactic courses were given between } 20^{\text {th }}-24^{\text {th }}}$ and $32^{\text {th }}-35^{\text {th }}$ weeks of pregnancy only to women with $\mathrm{PbB} \geq 2.0 \mu \mathrm{g} / \mathrm{dL}$.
} 


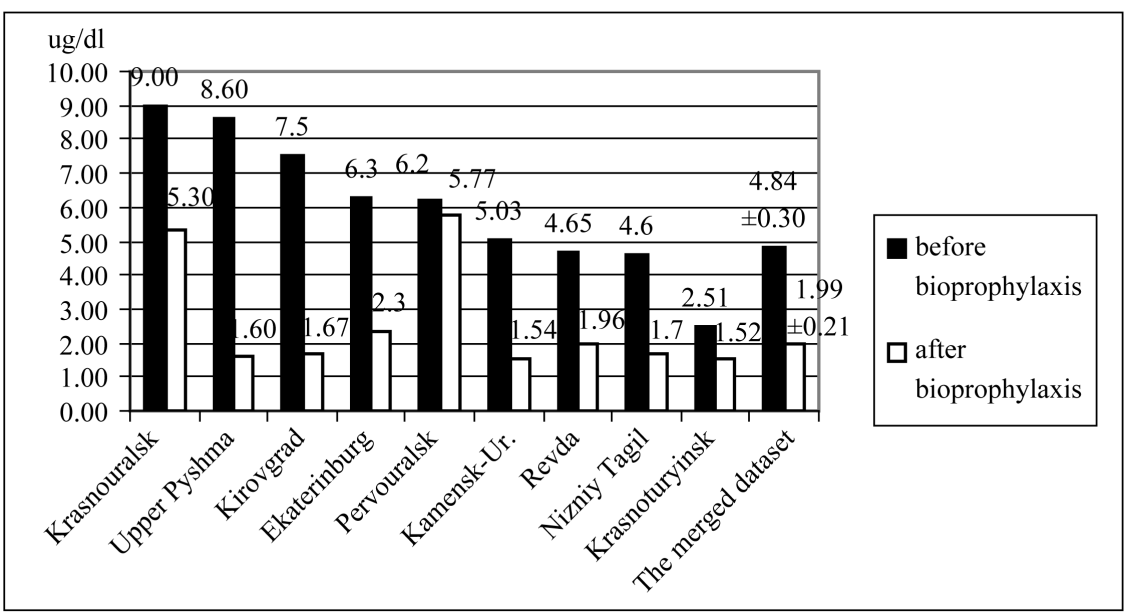

Figure 2. Mean lead concentration in the blood of pregnant women (2007 cohorts) before and after bio-prophylaxis. Differences between the levels before and after bioprophylaxis across the whole dataset are statistically significant for $\mathrm{P}<0.001$ (by the paired $t$-test).

the sub-chronic nephrotoxicity of lead is higher as compared with that of cadmium; c) the type of these two metals combine toxicity is very complicated with manifestation of both antagonism and synergy [27]; d) a complex of bio-protectors comprising pectin, glutamate, a multivitamin and multi-mineral preparation, and a calcium supplement attenuates the combined nephrotoxicity of these metals [9].

Later on (in 2006) we examined 38 children aged 3 - 7 in a fifth town also polluted with emissions from a big copper smelter [28]. Beside the above mentioned renal effect index, we performed liquid crystallography of urine. All the tests in this cohort were performed just before and immediately after the 5 weeks period during which the children were being given the same bio-protective complex that had been shown to protect laboratory rats against $\mathrm{Cd}-\mathrm{Pb}$ nephrotoxicity. In this cohort, only 5 children (13.2\%) had pre-treatment B2u levels above $300 \mu \mathrm{g} / \mathrm{L}$ but many children were found to have micro-urolithiasis observable with polarization microscopy (in $86.8 \%$ of children) which revealed also the formation of birefringent lipoprotein crystals characteristic of renal membranolysis of different extent (in 100\%) and the presence of an albuminous ring around the microscopy preparation (in 65.7\%). One third of the group had an abnormally high urine specific gravity (>1025). After the bio-protective intervention the prevalence of all these indices of renal damage as well as concentrations of Cd and $\mathrm{Pb}$ in the urine diminished statistically significantly $(\mathrm{P}<0.05)$.

Example 3.

During many years the town of Karpinsk has been characterized by a considerably higher incidence of cancer compared with other, even more industrialized cities and towns of Sverdlovsk Region. In the past, a small copper smelter and, later on, a chromate plant were active in this town, but the former was closed ca. 200 years, and the latter about 100 years ago. At a distance of $9 \mathrm{~km}$ leeward of Karpinsk a large aluminum electrolysis plant releases PAH-containing emissions, but the cancer morbidity in Karpinsk is higher than in a town situated close to that plant. In the meantime, a case-control epidemiological study has revealed a significant role of a range of individual cancer risk factors (Table 5) and, in particular, of an unusually high prevalence of coal furnaces in homes [29]. Bearing in mind the problem of anti-cancer bio-protection, it seems interesting that preferable use of milk-vegetable-fish diets was shown to be a protective factor decreasing the risk of colorectal cancer. It is well known that, in general, "a vegetable to meat consumption ratio is a relevant factor determining cancer preventive effect" [30]. We have no data to specify which vegetables are usually included in diets here, but it is above serious doubt that apples (not only imported but widely produced by the Ural individual gardeners) are, while the beneficial role just of apples for protection from colorectal cancers is epidemiologically established [31]. As to fish, its oil is notably rich in PUFA of the omega-3 group and so can be regarded as a DNA-protecting factor. (It is well known that omega-3-rich seafood is included now in all cancer-preventive dietological recommendations). On the other hand, we found that in Karpinsk preference for fat-rich food enhanced the risk of breast cancer, which is also consistent with literature data summarized by Sugimura [32]. 
Table 5. A summary of the main results of the case-control study on individual cancer-risk factors ${ }^{1)}$ in Karpinsk (Sverdlovsk region, Russia).

Lung, gastric and colorectal cancers

A. The most important factors increasing probability of cancer common for all the three sites:

1. SMOKING - especially of cigarettes without filters; more than 20 cigarettes a day; a long history of smoking.

2. OVERINDULGENCE IN ALCOHOL.

3. EMPLOYMENT IN ANY INDUSTRY.

4. "UNCOMFORTABLE" HOUSING (no piped water supply, poor sanitation, use of indoor coal burners for heating, water boiling and especially for cooking).

5. COAL-FIRED KITCHEN OVEN (irrespective of housing type).

6. BEING A PERMANENT RESIDENT (as opposed to immigrant).

For lung cancer only: CHRONIC BRONCHITIS.

For gastric cancer only: CHRONIC GASTRITIS AND GASTRIC ULCER.

For colorectal cancer only: LIVER DISEASES.

B. Factor decreasing probability of gastric and colorectal cances: PREFERRING MILK-VEGETABLE-FISH DIETS.

Breast cancer

A. Factors increasing probability of cancer:

1. HISTORY OF OTHER (BUT ESPECIALLY OF GYNECOLOGICAL) CANCERS.

2. HISTORY OF SURGERY ON BREASTS and/or OF MASTITIS.

3. OVERINDULGENCE IN ALCOHOL.

4. PREFERRENCE FOR FAT-RICH FOOD.

5. HAVING NEVER BEEN MARRIED.

6. LATE FIRST CHILDBIRTH.

7. HAVING NEVER BREAST-FED.

8. ENDOCRINE DISEASES.

9. LIVING IN A NON-TIMBER HOUSE.

10. COAL-FIRED KITCHEN OVEN.

11. BEING A PERMANENT RESIDENT (as opposed to immigrant).

B. Factors decreasing probability of cancer:

1. Childbirth ever.

2. Moderate alcohol drinking.

3. Liver diseases (negatively correlated with preference for fat-rich food).

${ }^{1)}$ Only those individual risk factors are given for which the adjusted odds ratio differs from 1.0 statistically significantly (P between $<0.05$ and $<0.001)$.

Then we found in an experiment that in rats exposed to subchronic intoxication with a combination of toxic and mutagenic metals (lead-arsenic-chromium-nickel-cadmium) in a ratio characteristic of the stable soil contamination in this town, as well as to fluoride and benzo(a)pyrene, a BPC comprising glutamate, pectin enterosorbent, a multivitamin-multimineral preparation and calcium additive significantly reduced the genotoxic effect [21]. The inclusion into this BPC of a bioactive fish oil preparation rich in polyunsaturated fatty acids pertaining mainly to the omega-3 group enhanced the antigenotoxic action.

Then the results of a special survey conducted with the help of a questionnaire in the female population of the most polluted areas of Karpinsk were analyzed (allowing for earlier established risk factors for the development of lung, GIT and breast cancer in this town demonstrated by Table 5) to form a group of the presumably highest cancer risk. From this group we selected, using targeted medical examination, women who did not have cancer of any type. These volunteers were administered a one-month course of a similar BPC or a placebo. Along with a lot of beneficial clinical effects of the BPC, it was found that tests for enhanced DNA repair provided positive dynamics only in the group who received the BPC [21] [33]. In particular, results of the Comet Assay are presented diagrammatically by Figure 3.

After this field trial had thus demonstrated beneficial effects of the BPC, it was given to the placebo group members — a usual ethical approach of all our studies

\section{Broad Implementation of Bioprophylaxis, Its Funding and Ethics}

Successful field trials prompt us to run similar biopreventive courses on broader populations not only in the same town but also in other cities and towns with similar environmental problems. This constitutes the final stage in the implementation of the system of bioprophylaxis in our region. So far, the greatest advance has been achieved for pregnant women (see above) and for children of preschool age. The scale of this work in the Sverdlovsk Region has been growing steadily although has somewhat diminished during last year due to economic 


\section{Group of volunteers administered the BPC}

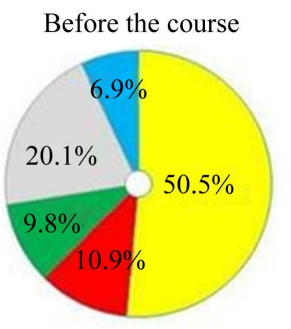

Before the course

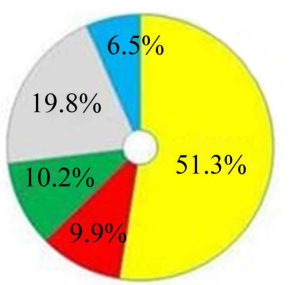

$\square \mathrm{C} 1$

$=\mathrm{C} 2$

$\because \mathrm{C} 3$

$\square \mathrm{C} 4$

an $\mathrm{C} 5$

Group of volunteers administered a placebo

$\square \mathrm{C} 1$

a $\mathrm{C} 2$

$\because \mathrm{C} 3$

$\square \mathrm{C} 4$

뜰 5

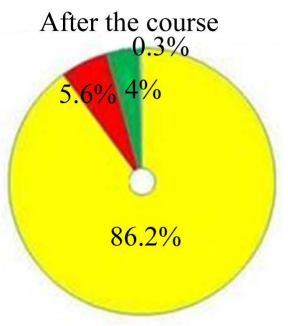

After the course

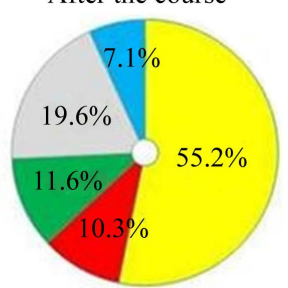

Figure 3. Results of the comet assay on circulating blood leukocytes of Karpinsk female dwellers before and after the BPC or placebo course: percentage of persons classified according to DNA fragmentation's degree (from C1-undamaged DNA to C5-completely fragmented DNA).

problems (Figure 4). However, during the same years it was carried out by us also in some cities outside our Region, such as Vladikavkaz (North Ossetia) and Mednogorsk (Orenburg Region). We began also to use the same bioprophylactic approach to occupational risks management (e.g. in the asbestos industry).

The further expansion of this program to cover wider subpopulations under risk and to increase the number of courses of bioprophylaxis per person is limited only by financial constraints. In this connection, it should be noted that our work (experimental included) presented in this paper has been financed at first stages almost entirely by the Regional Government and/or by municipal administrations from the budget of Ecological Funds to which the industry made the most substantial contribution; but now it is predominantly financed by the industry directly. Anyway, so far it has been free of charge for the citizens, and we maintain that it would be unethical otherwise: people should not be made pay for protecting themselves from harm inflicted by industry.

Another ethical aspect: we do not intend to calm down people's concern about the occupational and environmental risks, and always stress that bio-prophylaxis is not an alternative but only a supplement to technical and organizational ways of environmental and occupational risks management which should be considered obligatory.

The last but not the least: people should understand just what they are being given, why and to what end, and be able to make their own informed choice: to take proposed bioprotectors or not. Therefore we do our best to inform the populations of the industrial cities and towns and employees of harmful industrial enterprises about the significance of biological prophylaxis, its rationale and its results. Thus, about $10 \%$ of children receiving BPCs are chosen each year by local pediatricians (without our interfering) and examined by them before and after this treatment so as to check their general health status, which is found to have improved in $70 \%-80 \%$ of those who had had specific signs or symptoms. The parents' opinion is being pooled with the help of anonymous questionnaires and proved highly favourable in virtually $100 \%$.

\section{Conclusion}

To conclude, we believe that our experience of implementing the biological prophylaxis projects described in this paper should be used for expanding its scope both within and outside the Ural region. We do not maintain that this is the only possible or even the best possible tool for beneficial intervention into the cause-effect associations between chemical environmental pollution and disease, but we have shown that it can be really a useful way to proceed from the observational and analytical environmental epidemiology to the interventional one and thus to efficient public health protection. 


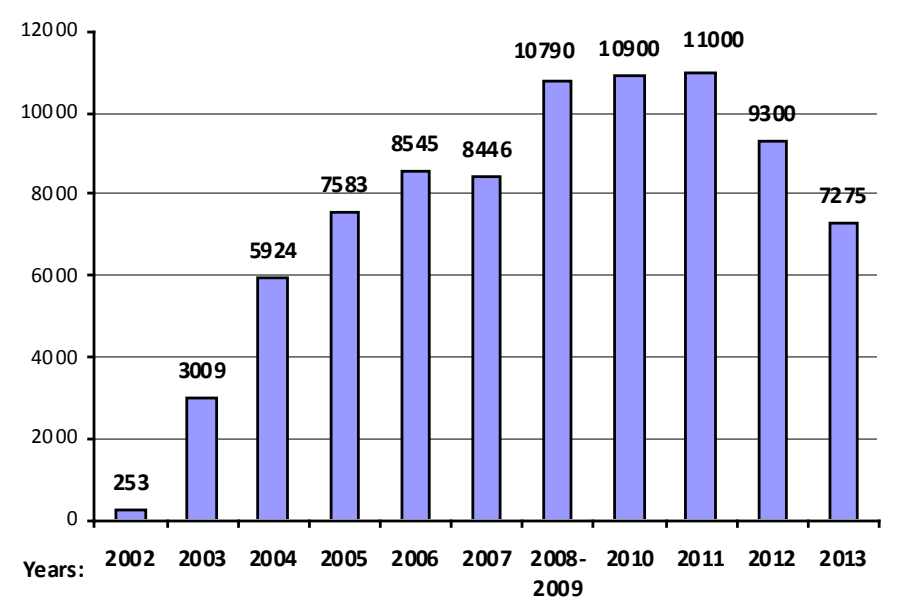

Figure 4. Number of children-dwellers of Middle Ural townships included into the bio-prophylactic project during 2002-2013.

\section{Acknowledgements}

The preparation of this paper was financed by the Ekaterinburg Medical Research Centre for Prophylaxis and Health Protection in Industrial Workers.

The authors declare that there are no conflicts of interest.

\section{References}

[1] Katsnelson, B.A., Degtyareva, T.D. and Privalova, L.I. (2004) Development of Means Increasing Resistance of the Organism to the Effect of Inorganic Pollutants of Industrial and Natural Environments. Russia, Ross Khim Zh, 48, 65-71.

[2] Katsnelson, B.A., Polzik, E.V. and Privalova, L.I. (1986) Some Aspects of the Problem of Individual Predisposition to Silicosis. Environmental Health Perspectives, 68, 175-185. http://dx.doi.org/10.1289/ehp.8668175

[3] Katsnelson, B.A., Alekseyeva, O.G., Privalova, L.I. and Polzik, E.V. (1995) Pneumoconioses: Pathogenesis and Biological Prophylaxis. Ural Division of the Russian Academy of Sciences Russia, Ekaterinburg.

[4] Polzik, E.V., Katsnelson, B.A., Kochneva, M.Yu. and Kasantsev, V.S. (1990) The Principles of Predicting the Individual Risk of Silicosis and Silicotuberculosis. Med Lav, 81, 87-95.

[5] Polzik, E.V., Katsnelson, B.A., Yakusheva, M.Yu. and Kasantsev, V.S. (1993) A Follow-Up on Workers with Predicted Individual Susceptibility to Silicosis. Med Lav, 84, 249-255.

[6] Morosova, K.I., Katsnelson, B.A., Rotenberg, Yu.S. and Belobragina, G.V. (1984) A Further Experimental Study of the Antisilicotic Effect of Glutamate. Br J Ind Med, 41, 518-525.

[7] Privalova, L.I., Katsnelson, B.A., Sutunkova, M.P., Valamina, I.E., Beresneva, O.Yu., Degtyareva, T.D. and Yeremenko, O.S. (2007) Attenuation of Some Adverse Health Effects of Chrysotile Asbestos with a Bioprotective Complex in Animal Experiments. Cent Eur J Occup Environ Med, 13, 3-14.

[8] Katsnelson, B.A., Yeremenko, O.S., Privalova, L.I., Makeyev, O.H., Degtyareva, T.D., Beresneva, O.Y. and Nazukin, A.S. (2009) Toxicity of Monazite Particulate and Its Attenuation with a Complex of Bio-Protectors. Med Lav, 100, 455-470.

[9] Kireyeva, E.P., Katsnelson, B.A., Degtyareva, T.D., Privalova, L.I., Valamina, I.E., Beresneva, O.Yu. and Denisenko, S.A. (2006) Nephrotoxic Effect of Lead and Cadmium and Its Inhibition by a Set of Bioprotectors. (Russian). Toxicol Vest, 6, 26-32.

[10] Degtyareva, T.D., Katsnelson, B.A., Minigalieva, I.A., Soloboeva, Yu.I., Brezgina, S.V., Beresneva, O.Yu. and Makarenko, N.P. (2007) Biological Prevention of Combined Effect of Toxic Metals and Organic Substances. Russia, Gig Sanit, 3, 37-40.

[11] Katsnelson, B.A., Privalova, L.I., Kireyeva, Y.P., Yeremenko, O.S., Sutunkova, M.P., Valamina, I.E., Varaksin, A.N., Panov, V.G. and Kazmer, J.I. (2012) Combined Subchronic Fluoride-Lead Intoxication and Its Attenuation with the Help of a Complex of Bioprotectors. La Medicina del lavoro, 103, 146-159.

[12] Katsnelson, B.A., Degtyareva, T.D., Privalova, L.I., Denisenko, S.A., Beresneva, O.Yu., Soloboeva, Yu.I. and Mi- 
nigalieva, I.A. (2005) Biological Prophylaxis as a Complex Influence upon an Organism Increasing Its Resistance against Exposure to Chemical Hazards of Occupation and Environment. Russia, Vestn Ural Med Akad, 2, 70-76.

[13] Katsnelson, B.A., Privalova, L.I., Gurvich, V.B., Makeyev, O.H., Shur, V.Ya., Beikin, Ya.B., Tulakina, L.G., et al. (2013) Comparative in Vivo Assessment of Some Adverse Bioeffects of Equidimensional Gold and Silver Nanoparticles and the Attenuation of Nanosilver's Effects with a Complex of Innocuous Bioprotectors. International Journal of Molecular Sciences, 14, 2449-2483.

[14] Privalova, L.I., Katsnelson, B.A., Loginova, N.V., Gurvich, V.B., Shur, V.Y., Valamina, I.E., Kostykova, S.V., et al. (2014) Subchronic Toxicity of Copper Oxide Nanoparticles and Its Attenuation with the Help of a Combination of Bioprotectors. International Journal of Molecular Sciences, 15, 12379-12406. http://dx.doi.org/10.3390/ijms150712379

[15] Katsnelson, B.A., Degtyareva, T.D., Privalova, L.I., Minigaliyeva, I.A., Slyshkina, T.V., Ryzhov, V.V. and Beresneva, O.Y. (2013) Attenuation of Subchronic Formaldehyde Inhalation Toxicity with Oral Administration of Glutamate, Glycine and Methionine. Toxicology Letters, 220, 181-186. http://dx.doi.org/10.1016/j.toxlet.2013.04.024

[16] Degtyareva, T.D., Privalova, L.I., Katsnelson, B.A., Beresneva, O.Yu., Denisenko, S.F. and Bukharova, G.Sh. (2002) Estimation of the Influence of Sodium Glutamate and Saparalum on the Cytotoxic Action of Particles of Low Soluble Compounds of Some Toxic Metals. Russia, Topical Issues in Preventive Medicine in the Ural Region (Collected Research Papers), Medical Research Center of Prophylaxis, Ekaterinburg.

[17] Degtyareva, T.D., Katsnelson, B.A., Privalova, L.I., Gurvich, V.B., Denisenko, S.A., Beresneva, O.Yu. and Makarenko, N.P. (2004) An Experimental Trial of an Iron-Containing Biopreventive Complex Inhibiting the Development of Harmful Environmental Effects of Lead in Combination with Other Toxic Metals. Russia, Contemporary Issues in Preventive Medicine, Environment and Public Health in Industrial Regions of Russia, (Onishchenko, G.G., Ed.), Medical Research Center of Prophylaxis, Ekaterinburg.

[18] Degtyareva, T.D., Katsnelson, B.A., Privalova, L.I., Beresneva, O.Y., Konysheva, L.K. and Demchenko, P.I. (2000) Estimation of the Effectiveness of Biological Prevention agents Lead Intoxication (An Experimental Study). Russia, Med tr prom ekol, 3, 40-43.

[19] Katsnelson, B.A., Degtyareva, T.D. and Privalova, L.I. (1999) Principles of Biological Prevention of Occupational and Environmental Pathology Due to the Impact of Inorganic Substances. Russia, Medical Research Center of Prophylaxis, Ekaterinburg.

[20] Katsnelson, B.A., Degtyareva, T.D., Privalova, L.I., Medvedeva, S.J., Gurvich, V.B. and Denisenko, S.A. (2004) Inhibition of General Toxic and Thyreotoxic Action of a Combination of Environmental Contaminants-Metals with a Complex of Bioprotective Agents. Russia, Toxicol Vest, 2, 23-29.

[21] Katsnelson, B.A., Makeyev, O.H., Kochneva, N.I., Privalova, L.I., Degtyareva, T.D., Bukhantsev, V.A. and Dovzhenko, E.I. (2007) Testing a Set of Bioprotectors against the Genotoxic Effect of a Combination of Ecotoxicants. Central European Journal of Occupational and Environmental Medicine, 13, 251-264.

[22] Degtyareva, T.D. (2001) The Influence of Biotic Doses of Copper on the Development of Lead Intoxication in Experiment. Russia, Occupational Medicine and Industrial Ecology (Collected Research Papers), (Domnin, S.G., Ed.), Medical Research Center of Prophylaxis, Ekaterinburg.

[23] Katsnelson, B.A., Privalova, L.I., Kuzmin, S.V., Malykh, O.L., Gurvich, V.B., Voronin, S.A. and Soloboeva, Yu.I. (2008) Lead and Childhood: Risks and Their Management (the Middle Urals Experience). Central European Journal of Occupational and Environmental Medicine, 14, 3-25.

[24] Ettinger, A.E., Lamadrid-Figueroa, H., Téllez-Rojo, M.M., Mercaso-Garcia, A., Peterson, K.E., Schwartz, J., Hu, H. and Hernández-Avila, M. (2009) Effect of Calcium Supplementation on Blood Lead Level in Pregnancy: A Randomized Placebo-Controlled Trial. Environmental Health Perspectives, 117, 26-31. http://dx.doi.org/10.1289/ehp.11868

[25] Akhter, S., Momen, M.A., Rahman, M.M., Parveen, T. and Karim, R.K. (2010) Effect of Maternal Anemia on Fetal Outcome. Mymensingh Medical Journal, 19, 391-398.

[26] Katsnelson, B.A., Kireyeva, E.P., Kuzmin, S.V., Privalova, L.I., Burns, K.M., Khrushcheva, N.A. and Denisenko, S.A. (2007) An Association between Incipient Renal Damage and Urine Cadmium and Lead Levels in Young Russian Children: A Case Control Study. European Epi Marker, 11, 1-8.

[27] Varaksin, A.N., Katsnelson, B.A., Panov, V.G., Privalova, L.I., Kireyeva, E.P., Valamina, I.E. and Beresneva, O.Y. (2014) Some Considerations Concerning the Theory of Combined Toxicity: A Case Study of Subchronic Experimental Intoxication with Cadmium and Lead. Food and Chemical Toxicology, 64, 144-156. http://dx.doi.org/10.1016/j.fct.2013.11.024

[28] Katsnelson, B.A., Privalova, L.I., Degtyareva, T.D., Kireyeva, E.P., Khrushcheva, N.A., Beikin, Ya.B. and Sutunkova, M.P. (2007) Correction of Certain Indices of Renal Function in Children Exposed to Lead and Cadmium as a Result of Using a Complex of Antitoxic Bioprotectors. Russia, Toxicol Vest, 6, 11-15.

[29] Katsnelson, B.A., Kochneva, N.I., Makeyev, O.H. and Privalova, L.I. (2008) Risk Factors for Cancer in a Small Russian Town with Unusually High Cancer Morbidity Rates and the Search for Biological Protection of Its Residents. 
Central European Journal of Occupational and Environmental Medicine, 14, 53-54.

[30] Kapiczewska, M. (2006) A Vegetable to Meat Consumption Ratio as a Relevant Factor Determining Cancer Preventive Diet. The Mediterranean versus Other European Countries. Forum of Nutrition, 59, 130-157. http://dx.doi.org/10.1159/000095211

[31] Jedrychowski, W. and Maugeri, U. (2008) An Apple a Day May Hold Colorectal Cancer at Bay. A Recent Evidence from Case-Control Study. European Epi Marker, 12, 1-8.

[32] Sugimura, T. (2002) Food and Cancer. Toxicology, 181-182, 17-21. http://dx.doi.org/10.1016/S0300-483X(02)00250-0

[33] Katsnelson, B.A., Makeyev, O.G., Kochneva, N.I., Degtyareva, T.D., Privalova, L.I., Beresneva, O.Yu. and Kireyeva, E.P. (2008) A Controlled Trial on Female Volunteers of a Set of Biological Protectors against Environmentally Caused Toxic and Carcinogenic Risk. Russia, Toxicol Vest, 3, 12-19. 
Scientific Research Publishing (SCIRP) is one of the largest Open Access journal publishers. It is currently publishing more than 200 open access, online, peer-reviewed journals covering a wide range of academic disciplines. SCIRP serves the worldwide academic communities and contributes to the progress and application of science with its publication.

Other selected journals from SCIRP are listed as below. Submit your manuscript to us via either submit@scirp.org or Online Submission Portal.
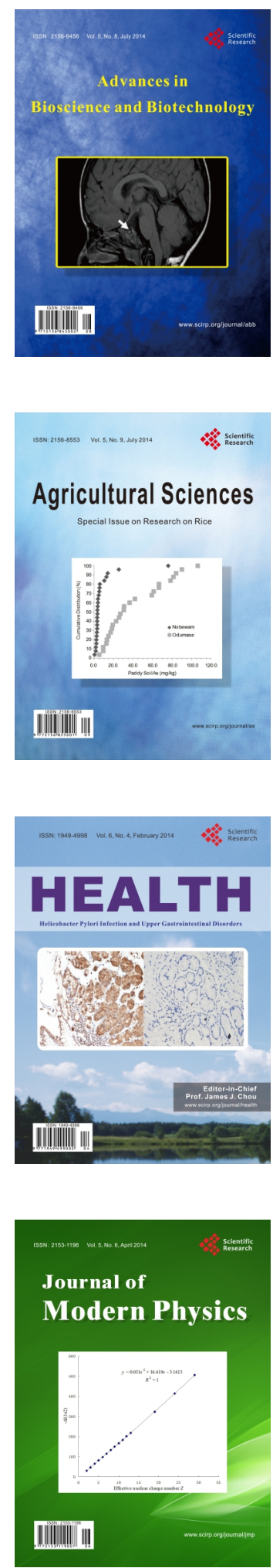
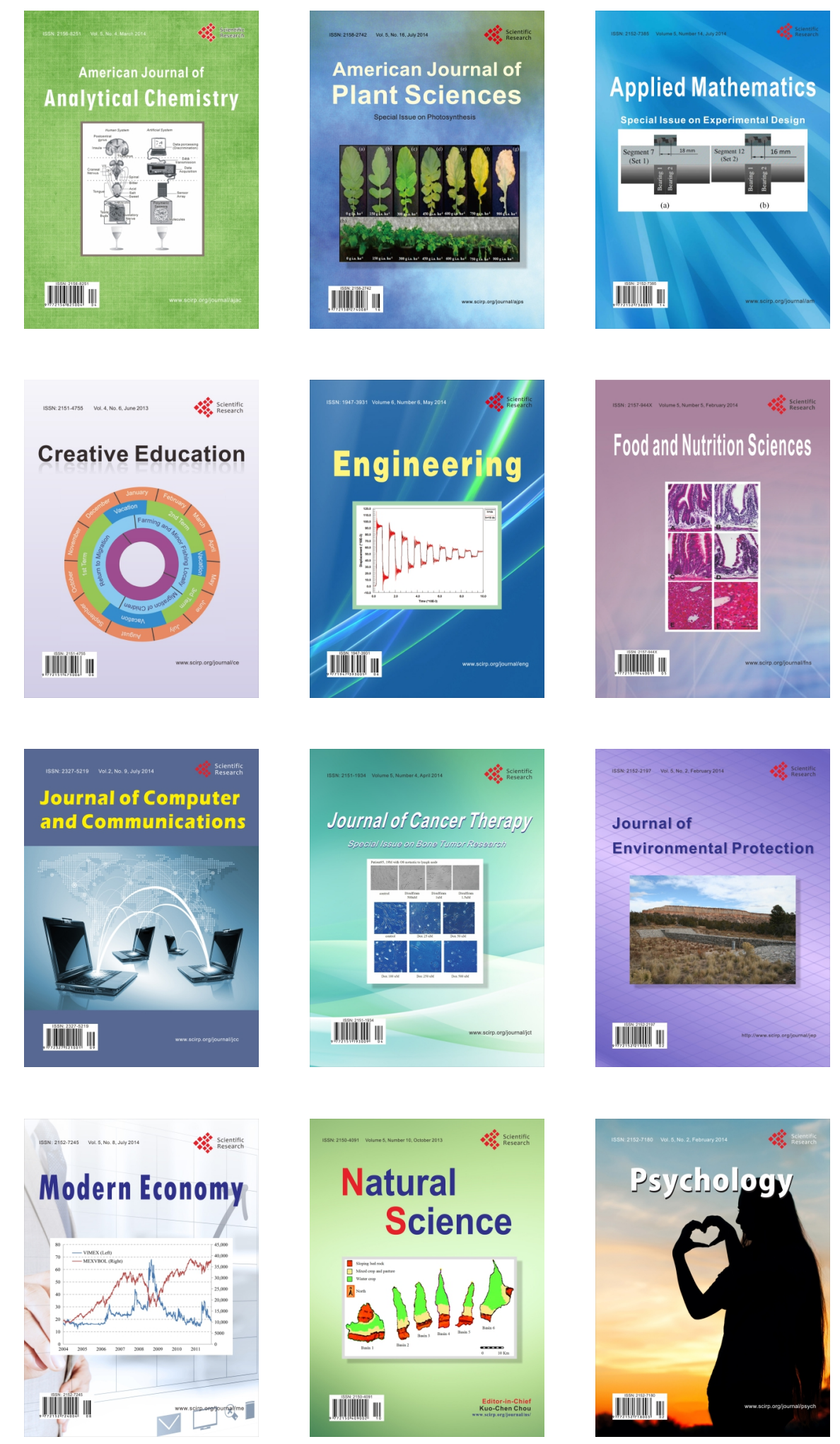